\title{
A IMPORTÂNCIA DA GOVERNANÇA CORPORATIVA E CONTROLES INTERNOS NAS ORGANIZAÇÕES
}

\section{ARTIGO DE REVISÃO}

CORREIA, Priscila de Oliveira ${ }^{1}$, LOPES, Paulo Fernando Pereira ${ }^{2}$, VICTORINO $^{2}$ JUNIOR, Delmir ${ }^{3}$

CORREIA, Priscila de Oliveira. LOPES, Paulo Fernando Pereira. VICTORINO JUNIOR, Delmir. A importância da governança corporativa e controles internos nas organizações. Revista Científica Multidisciplinar Núcleo do Conhecimento. Ano 06, Ed. 09, Vol. 03, pp. 64-79. Setembro de 2021. ISSN: 2448-0959, Link de acesso: https://www.nucleodoconhecimento.com.br/administracao/corporativa-e-controles, DOI: 10.32749/nucleodoconhecimento.com.br/administracao/corporativa-e-controles

\section{RESUMO}

Frente ao contexto econômico e político atual é de extrema importância que se conheça as modificações que estão incidindo na estrutura e na organização das instituições, pois é através dos seus mecanismos de atuação que se fundamenta toda a sua existência dentro de um mercado. Diante destes fatos enfatiza-se que, a governança corporativa é de extrema importância para o equilíbrio destas dificuldades, bem como nas tomadas de decisões dos gestores e das contas, como método ou mecanismo para impulsionar e controlar possíveis prejuízos financeiros oriundos de conflitos de interesses entre administradores e administrados. Desse modo, o tema do presente estudo é importância da governança corporativa nas organizações. Como problema de pesquisa tem-se a seguinte questão: as empresas tendem a buscar novas técnicas administrativas de modo a gerir de forma mais eficaz seus procedimentos. Dessa forma, qual a importância da governança corporativa e controles internos nas organizações? O presente estudo tem por

\footnotetext{
${ }^{1}$ Graduanda em Administração Pública.

2 Bacharel em Direito.

${ }^{3}$ Graduando em Administração Pública.
}

RC: 96930

Disponível em:

https://www.nucleodoconhecimento.com.br/administracao/corporativa-e-controles 
objetivo compreender a importância das boas práticas de Governança nas organizações tratando, em especial, da importância dos controles internos tanto contábeis quanto financeiros, visa ainda, retratar a relação de poder nas organizações e sua relação com a governança. Pode-se concluir que a cada dia, observam-se instituições buscando melhorias em seu desempenho e funcionamento econômico, sendo com isto cada vez mais eficiente e eficaz. Assim, a governança pode ser entendida como um sistema pelo qual as empresas são dirigidas e monitoradas, envolvendo os relacionamentos entre os escalões competentes e demais partes interessadas portanto, esta demanda de uma intensa definição de responsabilidade e compreensão dos relacionamentos entre as partes interessadas da organização, bem como aos responsáveis por administrar seus recursos e produzir seus resultados.

Palavras-Chaves: COSO, Governança, Desempenho, Administração.

\section{INTRODUÇÃO}

No final de 2016, o Governo aprovou o Decreto Federal №. 8945/16 que regulamenta e esclarece alguns aspectos da Lei. Segundo o Decreto Federal, as empresas sujeitas à Lei o 13.303 terão até junho de 2018 para promover as adaptações necessárias, o que significa que estas empresas terão um curto período para planejar e assumir mecanismos e práticas de GRC 2 proporcionais à relevância, à materialidade e aos riscos do negócio. Esta lei foi objeto de ações complementares por parte do Governo, conforme mencionado em publicação da KPMG intitulada Lei das Estatais - Lei oㅜ 13.303/16.

Nesse sentido, a legislação destaca a necessidade de boas práticas de Governança, buscando maior transparência e aprimoramento da dinâmica e do relacionamento com as partes interessadas.

Desta forma, as empresas precisarão se adaptar, objetivando dentre vários aspectos, uma melhor segurança das informações, comunicação tempestiva, 
equidade e prestação de contas, impulsionando assim as organizações a almejarem ferramentas de controles internos para garantir maior eficiência na governança corporativa.

Num cenário econômico e político que exige cada vez mais mudanças internas e externas dentro das companhias, essa mudança legislativa implica na necessidade de uma abordagem integrada por essas sociedades, devido aos novos requisitos que se apresentam, que envolvem e impactam toda a sua estrutura organizacional.

Esses novos requisitos, impostos pela lei 13.303/16 e decreto 8.495/16, devem ser analisados criteriosamente e fornecerem as bases prévias de um processo de avaliação e diagnóstico, que habilite a sociedade a sua posterior adequação às novas exigências e padrões de GRC.

Dessa forma, o presente artigo teve como questão norteadora: qual a importância da governança corporativa e controles internos nas organizações?

Tem por objetivo compreender a importância das boas práticas de Governança nas organizações tratando, em especial, da importância dos controles internos tanto contábeis quanto financeiros, visa ainda, retratar a relação de poder nas organizações e sua relação com a governança.

Segundo Almeida (2006, p. 50), “o controle interno simboliza em uma organização o conjunto de procedimentos, métodos ou rotinas com os objetivos de proteger os ativos, produzir dados contábeis e confiáveis, ajudar a administração na condução ordenada dos negócios da empresa".

Fornecendo o embasamento técnico para essa prática, de extrema relevância para a governança de qualquer organização, vamos abordar os principais aspectos do COSO-ICIF[4], renomado framework e quase unanimidade mundial quando se fala de controles internos. Diante do discorrido o presente artigo pretende, a partir de alguns modelos e práticas de mercado atual discutir, à luz das principais características das empresas estatais e sociedades de economia mista e exigências

RC: 96930

Disponível em:

https://www.nucleodoconhecimento.com.br/administracao/corporativa-e-controles 
previstas na Lei 13.303/16 - Lei das Estatais e Decreto 8.945/16, a importância do Controle Interno para a Governança Corporativa dessas organizações.

Para atingir seus objetivos, a pesquisa científica depende de um conjunto de procedimentos intelectuais e tecnológicos, o chamado método científico (SILVA e MENEZES, 2005). Silva e Menezes (2005), que apontam que o método científico é uma série de procedimentos ou operações intelectuais que devem ser utilizados nas investigações. Este é o método de raciocínio utilizado no processo de pesquisa.

Portanto, esta é uma revisão da literatura, cujo objetivo é reunir, avaliar e investigar artigos científicos que articulam o tema proposto do estudo.

\section{GOVERNANÇA CORPORATIVA - CONCEITOS}

O termo "governance" surge após ponderações do Banco Mundial em 2015, este definiu governança como o exercício da autoridade, controle, administração, poder de governo.

Segundo Diniz (2015, p. 400) "tal preocupação deslocou o foco da atenção das implicações estritamente econômicas da ação estatal para uma visão mais abrangente, envolvendo as dimensões sociais e políticas da gestão pública".

Conforme o Instituto Brasileiro de Governança Corporativa (IBGC, s.d), "Governança Corporativa são as práticas e os relacionamentos entre os Acionistas/Cotistas, Conselho de Administração, Diretoria, Auditoria Independente e Conselho Fiscal, com a finalidade de otimizar o desempenho da empresa e facilitar o acesso ao capital".

Sobre esse prisma, a Comissão de Valores Mobiliários (CVM, 2009) define governança corporativa como conjunto de práticas que tem por finalidade melhorar o desempenho de uma companhia e proteger todas as partes interessadas, como os investidores, empregadas e credores, facilitando o acesso ao capital.

RC: 96930

Disponível em:

https:/www.nucleodoconhecimento.com.br/administracao/corporativa-e-controles 
A governança pode ser entendida, portanto, como um sistema pelo qual as empresas são dirigidas e monitoradas, envolvendo os relacionamentos entre os escalões competentes e demais partes interessadas.

\subsection{PRINCÍPIOS DA GOVERNANÇA CORPORATIVA}

Os princípios de governança corporativa objetivam conservar os valores de uma organização e aumentar a credibilidade perante investidores. A companhia deve aderir os princípios para chances de continuidade de suas atividades e eficiência administrativa.

Conforme o IBGC, os princípios básicos da boa governança são:

- Transparência - Consiste no desejo de disponibilizar para as partes interessadas as informações que sejam de seu interesse e não apenas aquelas impostas por disposições de leis ou regulamentos. Não deve restringir-se ao desempenho econômico-financeiro, contemplando também os demais fatores (inclusive intangíveis) que norteiam a ação gerencial e que condizem à preservação e à otimização do valor da organização.

- Equidade - Caracteriza-se pelo tratamento justo e isonômico de todos os sócios e demais partes interessadas (stakeholders), levando em consideração seus direitos, deveres, necessidades, interesses e expectativas.

- Prestação de Contas (accountability) - Os agentes de governança devem prestar contas de sua atuação de modo claro, conciso, compreensível e tempestivo, assumindo integralmente as consequências de seus atos e omissões e atuando com diligência e responsabilidade no âmbito dos seus papéis.

RC: 96930

Disponível em:

https://www.nucleodoconhecimento.com.br/administracao/corporativa-e-controles 
- Responsabilidade Corporativa - Os agentes de governança devem zelar pela viabilidade econômico-financeira das organizações, reduzir as externalidades negativas de seus negócios e suas operações e aumentar as positivas, levando em consideração, no seu modelo de negócios, os diversos capitais (financeiro, manufaturado, intelectual, humano, social, ambiental, reputacional etc.) no curto, médio e longo prazos. (IBGC, s.d, online).

Organizações que adotam os princípios de governança corporativa e demonstram mais transparência, mantém controles mais efetivos, desenvolvem responsabilidade social, tem melhor visibilidade e credibilidade no mercado.

\subsection{CONTROLES INTERNOS}

O sistema de controle interno é o processo estruturado necessário para enfrentar riscos, conduzir a gestão e governança, além de fornecer a segurança para condução da realização dos objetivos relacionados a operações, divulgação, conformidade e missão da Companhia em seus objetivos a serem alcançados.

Para Crepaldi (2013, p. 472) o controle interno pode ser definido como:

O sistema de uma empresa, que compreende o plano de organização, os deveres e responsabilidades e todos os métodos e medidas adotados na empresa para salvaguardar seus ativos, verificar a exatidão e fidelidade dos dados contábeis, desenvolver a eficiência nas operações e estimular 0 seguimento das políticas administrativas prescritas.

Os controles internos são formas de precaver possíveis falhas nas mais diversas atividades das entidades, sejam operacionais, gerenciais ou financeiras.

Segundo Coso (2013, p. 06): "O controle interno é um processo conduzido pela estrutura de governança, administração e outros profissionais da entidade, e desenvolvido para proporcionar segurança razoável com respeito à realização dos objetivos relacionados a operações, divulgação e conformidade". 
Tendo em vista que as organizações buscam constantemente monitorar recursos financeiros, analisar desempenho, buscar eficácia e avaliar a produtividade, os controles internos representam assim procedimentos que podem de forma sistêmica fornecer métodos que propiciem ferramentas para a execução do devido monitoramento e desempenho das atividades organizacionais.

Cada organização requer um sistema básico de controle para monitorar seus recursos financeiros, desenvolver relações de trabalho, analisar seu desempenho e avaliar a produtividade operacional (CHIAVENATO, 2003).

O controle propicia a mensuração e a avaliação dos resultados da ação empresarial, representa um reflexo de todas as funções administrativas, proporciona uma garantia razoável, nunca uma garantia absoluta. Tem a finalidade de possibilitar o máximo de garantia nas seguintes categorias de objetivos.

Os controles internos podem ser:

- Preventivos: que são projetados para prevenir a ocorrência ou impacto de um erro, omissão ou ato malicioso.

- Detectivos: controles para detectar e reportar a ocorrência de um erro, omissão ou ato malicioso, após o fato.

- Corretivos: minimizam o impacto de um evento nocivo, isto é, quando o risco se materializa.

Os procedimentos adotados através dos Controles Internos têm como finalidade garantir: eficiência e eficácia das operações, confiabilidade das demonstrações financeiras e conformidade com a legislação e regulamentos vigentes, objetivando aderência às normas e políticas definidas pela organização. Deve-se atentar que, estes controles são de extrema significância para a organização, pois, veem a resguardar os bens de possíveis erros institucionais.

Segundo Almeida (2006, p. 50), o controle interno "é para uma organização o conjunto de procedimentos, métodos ou rotinas com os objetivos de proteger os 
ativos, produzir dados contábeis confiáveis e ajudar a administração na condução ordenada dos negócios da empresa".

Com a percepção da necessidade de um maior controle dentro das organizações, existe um aprimoramento para facilitar o trabalho da auditoria interna dentro da organização.

Attie (2008, p. 110) nos traz que:

Às vezes imagina-se ser o controle interno sinônimo de auditoria interna. É uma ideia totalmente equivocada, pois a auditoria interna é equivalente a um trabalho organizado de revisão e apreciação dos controles internos, normalmente executados por um departamento especializado, ao passo que o controle interno se refere a procedimentos de organização adotados como planos permanentes da empresa.

Conforme Tenório (2007, p. 43) "a preocupação com os controles internos se intensificou no início deste século, após grandes escândalos contábeis ocorridos em 2001 e 2002, e que as questões ligadas a controles são mais reativas do que proativas".

Portanto, o controle interno engloba a multiplicidade das incumbências para se alcançar um controle eficiente, sua compreensão nos níveis estratégicos, táticos e operacionais, assim como a introdução de controle em cada nível.

\subsection{OBJETIVOS E IMPORTÂNCIA DO CONTROLE INTERNO}

Crepaldi (2008, p. 65), denota que "é de extrema importância a utilização de um controle adequado sobre cada sistema operacional, pois desta maneira atingem-se os resultados mais favoráveis com menos desperdícios".

A apreciação do controle interno está intensamente relacionada a uma gestão de qualidade, tornando irrealizável a qualquer empresa tomar decisões baseada em informações que não sejam confiáveis ou passíveis de verificação.

RC: 96930

Disponível em:

https://www.nucleodoconhecimento.com.br/administracao/corporativa-e-controles 
Uma organização sem controle é inviável. Cada organização tem sistemas de controle que coordenam o exercício do direito de decisão que está diluído entre certo número de indivíduos. Os sistemas de controle também desempenham outra importante função na organização. Eles medem a eficácia com que as decisões são traduzidas em resultados. Essa segunda característica de controles internos relaciona-se ao alcance de metas da empresa. Nesse aspecto, os sistemas de controle tratam de influenciar o comportamento de indivíduos no interesse da empresa. Ambas as funções estão intimamente ligadas (CREPALDI, 2008, p. 47).

Ou seja, há uma garantia sobre fluxo correto de informações e operações, modificando os dados coletados em importantes ferramentas administrativas. Seus controles e mecanismos de revisão garantem, ainda, proteção contra erros, afasta a possibilidade de golpes e aproxima os colaboradores das políticas de gestão da organização.

De uma forma mais detalhada Oliveira et al. (2009, p.78) explicitam os principais objetivos do conjunto de sistema de controle interno:

a) verificar e assegurar os cumprimentos às políticas e regras da companhia, incluindo o código de ética nas relações comerciais e profissionais;

b) obter informações adequadas, confiáveis, de qualidade e em tempo de cumprir e, que sejam realmente úteis para as tomadas de decisões;

c) demonstrar a veracidade de informações e relatórios contábeis, operacionais e financeiros;

d) resguardar os ativos da entidade, o que compreende bens e direitos;

e) precaver erros e fraudes. Em caso de ocorrência dos mesmos, possibilitar a descoberta o mais rápido possível, determinar sua extensão e atribuições de certas responsabilidades;

f) servir como ferramenta para a posição de desperdícios, requerendo ao mesmo tempo a uniformidade e a correção;

g) registrar adequadamente as diversas operações, de modo a assegurar a eficiente utilização dos recursos da empresa;

h) estimular a efetividade do pessoal, mediante a vigilância exercida por meio de relatórios;

i) assegurar a legitimidade dos passivos da empresa, com o adequado registro e controle das provisões, perdas reais e previstas;

RC: 96930

Disponível em:

https://www.nucleodoconhecimento.com.br/administracao/corporativa-e-controles 
j) assegurar o processamento correto das transações da empresa, bem como a efetiva autorização de todos os fatos ocorridos no período; e

k) permitir a observância e estrito cumprimento da legislação em vigor.

Conforme Perardt (2011, p. 2) "este sistema proporciona a fiscalização e o acompanhamento das atividades, metas e objetivos, comparando o planejado com o executado, a efetividade na aplicação dos recursos, e a capacidade de avaliação e resposta ao risco inerente".

Segundo Attie (2015. p. 61), "um sistema de controle interno que funcione adequadamente constitui a melhor proteção, para a companhia, contra as fraquezas humanas". Portanto, não adianta a empresa apenas solicitar aos gestores a responsabilidade sobre as tarefas, deve-se haver mecanismos para a efetivação destas tarefas, não desdenhando aqui a credibilidade dos colaboradores, mas sim dando a oportunidade de auxílio no desenvolvimento profissional, haja vista a chance de verificar possíveis falhas com oportunidade de corrigi-las.

\subsection{O PODER NAS ORGANIZAÇÕES}

O poder nas últimas décadas tem sido estudado a partir de perspectivas políticas, psicológicas, sociológicas e organizacionais. Algumas definições de poder são citadas a seguir:

(1) Segundo Weber (2012) "Poder significa a probabilidade de impor a própria vontade dentro de uma relação social, mesmo contra toda resistência e qualquer que seja a base dessa probabilidade" (p. 43 )

(2) Lasswell e Kaplan (2010) definem poder de uma perspectiva organizacional como a participação na tomada de decisão, por exemplo, o sujeito $A$ tem poder sobre o sujeito $B$, no que diz respeito aos valores $K$, se $A$ participa da tomada de decisão que afeta $B$. as políticas de 
(3) Wrong (2008) definiu o poder como "controle deliberado e efetivo por agentes particulares" (p. 676);

Ele também o definiu como a capacidade de controlar os outros, encontrando três elementos-chave imersos nesta definição: a influência de alguns sobre os outros, a crença de que o poder não se limita à relação entre superiores e subordinados, mas também entre iguais e a ideia de que o a influência é consciente e intencional.

Para Pfeffer (2008) o controle conferido à autoridade não só faz com que o exercício do poder pareça menos arbitrário e notório, mas também reduz os custos do exercício do poder.

(4) Easton (2008) definiu o poder como um fenômeno de relacionamento, não como algo que é possuído. O poder é uma relação em que uma pessoa ou grupo de pessoas determina as ações dos outros, de forma que os desejos dos primeiros sejam satisfeitos.

(5) De um ponto de vista pluralista (BURREL e MORGAN, 2009) "poder é o meio pelo qual os conflitos de interesse são amenizados e resolvidos. A organização é vista como uma pluralidade de detentores de poder de uma pluralidade de fontes "( $p$. 204).

(6) Bourdieu (1989) define o poder simbólico como um instrumento legítimo de dominação invisível que só pode ser exercido com a cumplicidade voluntária de quem o sofre. Baseia-se na legitimidade da autoridade, alcançando o mesmo que com a força física ou econômica graças ao efeito da mobilização. É definida como uma relação específica entre quem exerce o poder e quem o sofre.

(7) Montbrun (2010) conceitua poder como "energia distribuída na rede" (p. 385); nesse sentido, a pluridirecionalidade é incorporada às relações sociais de uma organização, bem como à influência do meio ambiente. 
Também nos permite entender como, em certas situações, as mesmas pessoas agirão de maneiras imprevisíveis. Nas definições anteriores, são apresentados os seguintes elementos:

- No poder, apresenta-se a relação social entre pelo menos dois indivíduos ou grupos, onde o poder assenta numa base ou fundamento.

- Na maioria das definições, o exercício do poder é expresso como uma relação social assimétrica com uma forte unidirecionalidade; porém, nas definições de Wrong, Burrel, Morgan e Montbrun, o fenômeno da pluridirecionalidade nos relacionamentos, característico da teoria das redes, é reconhecido.

- Na definição de Weber inclui-se a probabilidade, ou seja, reconhece-se a incerteza que corresponde ao paradigma da complexidade. French e Raven (2009) classificam o poder como coercitivo, recompensador, legítimo ou burocrático, referente ou carismático, e no poder do especialista, esta última classificação tem servido de base nos estudos de liderança nas organizações.

Em vez disso, Etzioni (2005) classificou o poder como coercitivo, remunerador e normativo.

\subsection{GOVERNANÇA CORPORATIVA E PODER}

Cadbury (2012) definiu Governança Corporativa como o sistema pelo qual as empresas são dirigidas e controladas no desenvolvimento de suas atividades econômicas. O papel dos acionistas é nomear diretores e auditores e satisfazer uma estrutura de governança apropriada. Os órgãos de administração são responsáveis pela governança de suas empresas. As responsabilidades do conselho incluem definir os objetivos estratégicos da empresa, fornecer liderança para implementá-los, supervisionar a gestão da empresa e reportar aos acionistas sobre sua gestão. As ações do conselho de administração estão sujeitas às leis, regulamentos e ao conhecimento da assembleia geral de acionistas. 
O objetivo do Relatório Cadbury era melhorar o clima de investimento na Inglaterra. Para Shleifer e Vishny (2017), governança corporativa diz respeito a sistemas de controle para que quem fornece recursos financeiros a uma empresa garanta a rentabilidade adequada para seus investimentos; para isso, as organizações devem ser administradas de forma eficiente pelos gestores.

Segundo Méndez e Rivera (2015), governança corporativa consiste no conjunto de relações de poder que se estabelecem entre os membros de uma organização para garantir que cada um receba o que é justo. Pretende-se melhorar os aspectos que dizem respeito ao modelo de tomada de decisão, à composição do capital, aos sistemas de remuneração dos agentes e aos sistemas de controlo ou monitorização.

Robbins e Coulter (2005) definem governança corporativa como "o sistema usado para governar uma corporação de uma forma que proteja os interesses dos proprietários corporativos" (p.482).

Segundo Maya (2011), a governança corporativa consiste em um conjunto de normas, práticas e procedimentos por meio dos quais as relações que ocorrem dentro de uma organização corporativa são reguladas, em particular sobre os direitos e obrigações de seus membros, as regras que regem as decisões. fabricação e a forma como são operados e controlados.

Nas definições anteriores, a governança corporativa é concebida como um sistema de governança que protege exclusivamente os interesses dos proprietários e credores. A expressão "boa governança corporativa" apareceu nos Princípios de Governança Corporativa publicados pela Organização para Cooperação e Desenvolvimento Econômico, OCDE (2004), onde é mencionado que "a boa governança corporativa contribui para a estabilidade dos mercados financeiros, para o investimento e economia crescimento "(p.3).

Nesse sentido, a abordagem de "boa governança corporativa" está relacionada ao grau de cumprimento dos princípios de governança corporativa. A boa governança corporativa fornece os mecanismos que permitem um equilíbrio entre a gestão e o

RC: 96930

Disponível em:

https://www.nucleodoconhecimento.com.br/administracao/corporativa-e-controles 
controle dessa gestão através de sistemas de freios e contrapesos, para que as decisões adotadas sejam tomadas de acordo com o interesse superior da organização, dos acionistas, e respeitando os direitos das partes interessadas.

O referido torna a empresa mais atrativa para investidores e credores, abrindo a possibilidade de financiamento em bolsa a custos mais baixos, tornando-a mais rentável, eficiente e competitiva, longe da corrupção e da má gestão, aumentando o seu valor para benefício dos acionistas e afins. partes interessadas.

Ganga e Vera (2008) mencionam que "em termos gerais, boa governança corporativa pode ser entendida como a prática de uma filosofia corporativa, apoiada em processos adequados que permitem aos stakeholders de uma organização medir e avaliar os propósitos, riscos e oportunidades que surgem em uma empresa "(p.101). Levando em consideração os interesses dos envolvidos e das comunidades onde atuam, aumenta a confiança entre as partes, o que resulta no bem-estar da sociedade.

Para Morck (2014), governança corporativa é um sistema que regula e equilibra as relações de poder entre os acionistas majoritários e minoritários, executivos e Conselho de Administração, com o objetivo de aumentar a confiança dos stakeholders e aumentar os resultados econômicos, maximizando o valor da empresa.

Para a OCDE (2015), governança corporativa implica um conjunto de relações entre administradores de empresas, seus conselhos de administração, seus acionistas e outras partes interessadas. A governança corporativa também fornece a estrutura por meio da qual os objetivos da empresa são estabelecidos e os meios para atingir esses objetivos e monitorar o desempenho.

Esses elementos comuns foram formulados para abranger os diferentes modelos de governança corporativa que os países possuem. Os princípios de governança corporativa foram desenvolvidos para ajudar os legisladores a avaliar e melhorar a estrutura legislativa, regulatória e institucional da governança corporativa.

RC: 96930

Disponível em:

https://www.nucleodoconhecimento.com.br/administracao/corporativa-e-controles 
De acordo com a OCDE (2015), "Os princípios identificam claramente os fundamentos da boa governança corporativa e oferecem orientações práticas para sua aplicação em nível nacional” (p.7).

Em setembro de 2015, a Organização para a Cooperação e Desenvolvimento Econômico e o G20 publicaram uma versão atualizada dos Princípios de Governança Corporativa de 2004, com o objetivo de refletir a prioridade da defesa da boa governança como elemento de crescimento e desenvolvimento inclusivos. Para o efeito, foram tidas em consideração as lições de governo societário da crise financeira global de 2008, o aumento da atividade empresarial entre países e as alterações no funcionamento dos mercados de valores mobiliários.

Esses princípios estão estruturados em seis seções, os aspectos mais importantes são apresentados a seguir:

- A base para uma boa estrutura de governança corporativa: A estrutura de governança corporativa deve promover mercados justos e transparentes e uma alocação eficiente de recursos. Isso deve ser consistente com a estrutura legal e apoiado por uma aplicação eficaz de supervisão

- Os direitos e o tratamento equitativo dos acionistas e as principais funções de propriedade: A estrutura de governança corporativa deve proteger e facilitar o exercício dos direitos dos acionistas e garantir o tratamento equitativo de todos, incluindo acionistas minoritários e estrangeiros. Todos devem ter a oportunidade de obter uma compensação efetiva pela violação de seus direitos.

- Investidores institucionais, mercado de ações e outros intermediários: A estrutura de governança corporativa deve fornecer incentivos importantes em toda a cadeia de investimento e contribuir para o funcionamento do mercado de ações de uma forma que contribua para a boa governança corporativa.

- O papel dos grupos de interesse na governança corporativa: A estrutura de governança corporativa deve reconhecer os direitos dos grupos de interesse estabelecidos por lei ou por meio de acordos mútuos e encorajar a 
cooperação ativa entre empresas e grupos de interesse na criação de riqueza, emprego e sustentabilidade de empresas financeiramente sólidas. É reconhecido que os mecanismos de participação dos funcionários contribuem para melhorar a rentabilidade corporativa.

- Divulgação de informações e transparência: A estrutura de governança corporativa deve garantir a divulgação oportuna e precisa de informações sobre todos os assuntos importantes relacionados à empresa, incluindo a posição financeira, desempenho, propriedade e governança da empresa.

- As responsabilidades do Órgão de Administração: O quadro de governo societário deve assegurar uma orientação estratégica da empresa, um acompanhamento eficaz pela gestão da estratégia e a prestação de contas à empresa e às partes interessadas. Novas responsabilidades do conselho de administração surgem em relação ao planejamento tributário, gestão de riscos, papel dos diversos comitês do conselho de administração, função de auditoria interna, avaliações periódicas do conselho de administração e treinamento de seus membros. A importância da equidade de gênero é enfatizada na composição dos conselhos de administração. Os acionistas devem poder destituir administradores e participar do processo de seleção de candidatos a cargos de gestão.

Os princípios de governança corporativa fornecem às funções executivas e legislativas dos países, órgãos reguladores e de controle, e stakeholders internos e externos, orientações específicas para o aprimoramento dos órgãos jurídicos, regulamentos nos quais se baseia a governança corporativa, com foco na primeira instância nas empresas que são cotadas em bolsa, mas também nas não cotadas e em entidades do setor público.

Os princípios da boa governança corporativa é um documento flexível que é revisado levando em consideração as mudanças mais importantes que estão ocorrendo nas organizações e em seu ambiente. 


\section{CONCLUSÃO}

As transformações socioeconômicas ocorridas com o passar do tempo foram elementares para a exigência cada vez maior de profissionalização dentro deste tipo de organização.

Os controles internos são importantes para resguardar a empresa perante a prática de possíveis erros ou até mesmo fraudes. Para que se tenha um bom andamento dos controles internos, irá depender também da eficiência de como eles são planejados e executados. Ou seja, esse procedimento representa todos os procedimentos e metodologias elaborados pela instituição a fim de que seu patrimônio seja protegido contra possíveis perdas. Para isso, utilizam-se ferramentas de apoio para a eficácia dos processos como a auditoria interna.

Todas as organizações estão sujeitas a enfrentar esses riscos, podendo os mesmos serem internos ou externos; o desafio das mesmas é obterem de forma eficaz o controle interno. Este deverá propiciar uma mensuração junto à avaliação dos resultados das ações empresariais representando um reflexo de todas as funções administrativas e proporcionando ainda uma garantia razoável, nunca uma garantia absoluta.

Diante do discorrido até o momento, afere-se que o controle interno deverá estar em todos os níveis da empresa, pois as ferramentas do mesmo favorecem o alcance dos objetivos almejados em qualquer área da organização, tendo a mesma influência positiva nas atividades operacionais desde que se saiba como, onde e quando controlar.

Conclui-se por fim que governança corporativa em um contexto amplo tem por objetivo primordial a integração entre todas as diretrizes das boas práticas de governança com a estruturação do gerenciamento de riscos, agregando assim valores éticos, sendo capaz ainda de identificar e propor soluções.

RC: 96930

Disponível em:

https://www.nucleodoconhecimento.com.br/administracao/corporativa-e-controles 


\section{REFERÊNCIAS}

ALMEIDA.; CALVACANTI, M. Auditoria: um curso moderno e completo. São Paulo: Atlas, 2006.

ATTIE, W. Auditoria Interna. 3aㅗ ed., São Paulo: Atlas, 2015.

ATTIE, W. Auditoria: conceitos e aplicações. 3aㅗ ed. São Paulo: Atlas, 2008.

BURREL, G. Y MORGAN, G. Sociological Paradigms and Organisational Analysis: Elements of the Sociology of Corporate Life. New York: Pearson Education,2009

CADBURY, A. The financial aspects of corporate governance.,2012 Disponivel em http:// www.ecgi.org/codes/documents/cadbury. Pdf

CHIAVENATO, I. Administração nos novos tempos. $2^{a}$ ed. Rio de Janeiro: Campus, 2003.

CREPALDI, S. A. Auditoria contábil: Teoria e prática. 4aㅡ ed. São Paulo: Atlas, 2008.

CREPALDI, S. A. Contabilidade gerencial: Teoria e Prática. 9ª ed. São Paulo: Atlas, 2013.

EASTON, D. Política moderna: un estudio sobre la situación de la ciencia política. México D.F: Letras,2008

ELI, D. Governabilidade, Democracia e Reforma do Estado: Os Desafios da Construção de uma Nova Ordem no Brasil dos Anos 90. In: DADOS - Revista de Ciências Sociais. Rio de Janeiro, volume 38, no 3, p. 385-41, 2015.

ETZIONI, A. A comparative analysis of complex organizations . New York: The free press,2005

RC: 96930

Disponível em:

https://www.nucleodoconhecimento.com.br/administracao/corporativa-e-controles 
FRENCH, J. Y RAVEN, B. The bases of social power. Oxford: Cartwright (Ed),2009 GANGA, F. Y VERA, J. El gobierno corporativo: Consideraciones y cimientos teóricos. Cuadernos de Administración, 21(35), 93- 126,2008 Disponivel em http://www.redalyc.org/ articulo.oa?id=20503505.

IBGC. INSTITUTO BRASILEIRO DE GOVERNANÇA CORPORATIVA. Princípios que geram valor de longo prazo. Disponível em: https://www.ibgc.org.br/conhecimento/governanca-corporativa.

LAKATOS, E. M.; MARCONI, M. A. Metodologia do trabalho científico. 4ª .ed. São Paulo: Atlas, 2012.

LASSWELL, H. Y KAPLAN, A. . Power and Society. Yale University Press,2010 Disponivel em http://www.policysciences.org/classics/ power_society.pdf.

MAYA, J. Gobierno corporativo en hospitales. Revista CES Salud Pública, 2(1), 91-101,2011.Disponivel em: https://dialnet. unirioja.es/descarga/articulo/3677241. Pdf

MÉNDEZ, J. Y RIVERA, H. Relación entre gobierno corporativo y posicionamiento organizacional: instituciones de educación superior en América Latina. Educación y Educadores, 18(3), 435-455,2015 Disponivel em http://www.redalyc.org/ pdf/834/83443150004.pdf.

MONTBRUN, A.Notas para una revisión crítica del concepto de "Poder".,2010 Revista de la Universidad Bolivariana, 367-389. doi:10.4067/S071865682010000100022 .

MORCK, R. The social value of shareholder value. Corporate governance an international review, 22(3), 185-193. doi:10.1111/ corg.1206,2014

OCDE. G20/OECD Principles of Corporate Governance,2015.Paris: OECD Publishing. doi:http://dx.doi. org/10.1787/9789264236882-en

RC: 96930

Disponível em:

https://www.nucleodoconhecimento.com.br/administracao/corporativa-e-controles 
OLIVEIRA, L. M., et. al. Controladoria estratégica. 4ạ. ed. São Paulo: Atlas, 2009.

PERARDT, S. Gestão de controles internos baseado no modelo COSO ERM: um estudo de caso em uma Instituição de Ensino Superior Pública. In: V Seminário UFPE de Ciências Contábeis, 2011, Recife. Anais. Recife: UFPE, 2011.

PFEFFER, J. Power in organizations. Cambridge, MA: Ballinger Publishing Company

Robbins, S. y Coulter, M. (2005). Administración (octava ed.). México: Pearson

SHLEIFER, A. Y VISHNY, R. A survey of corporate gobernance. Journal of finance, 12(2), 737- 783,2017. Disponivel em http://scholar.harvard. edu/files/shleifer/files/surveycorpgov.pdf.

SILVA, E. L.; MENEZES, E. M. Metodologia da pesquisa e elaboração de dissertação. 4a. ed. Florianópolis, 2005.

TENÓRIO, J. G. Controle interno: um estudo sobre sua participação na tomada de decisão de investimento no mercado de capitais brasileiro. Universidade de Brasília, Universidade Federal da Paraíba, Universidade Federal de Pernambuco e Universidade do Rio Grande do Norte, Recife, 2007.

WEBER, M. Economía y Sociedad (Segunda edición en español ed.). (J. WINCKELMANN, Ed., \& ]. R. JOSÉ MEDINA ECHAVARR1A, Trad.) Madrid: Fondo de Cultura Económica,2012 Disponivel em https://zoonpolitikonmx. files.wordpress.com/2014/08/max-webereconomia-y-sociedad.pdf.

WRONG, D. Some problems in defining social problems. Chicago: University of Chicago,2008 


\section{APÊNDICE - REFERÊNCIA NOTA DE RODAPÉ}

4. Denominado de Controle Interno - Estrutura Integrada, (Internal Control Integrated Framework). Trata-se de um modelo conceitual de grande aceitação e que tem sido aplicado amplamente em todo o mundo para a implantação, revisão ou adequação do sistema de controles internos. Constitui um material de referência extremamente útil para as organizações no desenvolvimento e na manutenção de sistemas alinhados aos objetivos do negócio e adaptados às constantes mudanças no ambiente empresarial. Leva o nome do comitê responsável pela sua elaboração, - Committee of Sponsoring Organizations of the Treadway Commission, que publicou a obra inicialmente em 2012 e a revisou em 2013.

Enviado: Junho de 2021.

Aprovado: Setembro de 2021.

RC: 96930

Disponível em:

https://www.nucleodoconhecimento.com.br/administracao/corporativa-e-controles 